\title{
ANALISIS IFE, EFE, DAN BALANCE SCORECARD PADA GRUP PERUSAHAAN PT KIRANA MEGATARA
}

\author{
Christian Chandra Kusuma \\ Program Studi Magister Manajemen Universitas Tarumanagara \\ christian_ceka@yahoo.com \\ Carunia Mulya Firdausy \\ Program Studi Magister Manajemen Universitas Tarumanagara
}

Masuk : 02-12-2017, revisi : 16-12-2017 diterima untuk diterbitkan : 16-12-2017

\begin{abstract}
This research objective is aimed to analyze and evaluate the internal and external factors of the company and to design the balance scorecard as an alternative of performance measurement tools to support the company's vision, mission, and strategy to achieve competitive advantage. The internal and external factors are to knowing what are the strengths and weaknesses of the company, also the opportunities and threats from the outside of the company. Based on the SWOT analysis, PT Kirana Megatara can identify the key success factors to compete with other companies in the same industry. Balanced Scorecard enables companies to record financial performance results as well as monitor progress in building the company's ability and to obtain intangible assets that required for future growth. Balance scorecard measures the performance of companies on the four perspectives of balanced: financial, customer, internal business processes, and learning growth to create strategy maps of the company. Based on the balance scorecard analysis, the current performance in PT Kirana Megatara is more focusing on financial perspective, which are growth of the sales and profitability increment. To achieve long term objective, PT Kirana Megatara should also concern of the other three perspectives of balance scorecard.
\end{abstract}

Keywords: Internal and External Factors, SWOT, Balance Scorecard, Strategy Map

\section{PENDAHULUAN}

Persaingan bisnis industri karet remah alam (crumb rubber) dirasakan semakin berat. Hal ini terlihat banyaknya persaingan antar perusahaan karet baik dalam negeri maupun luar negeri, serta turunnya harga karet dunia yang mempengaruhi jumlah pasokan karet alam dari petani. Namun, industri pengolahan karet alam menjadi produk karet remahan dengan nama produk Standard Indonesia Rubber (SIR) tetap menjadi salah satu primadona komoditi di dunia karena tingginya kebutuhan bahan karet di dunia, untuk diolah menjadi ban (tire) kendaraan. Salah satu grup pengolahan karet remahan terbesar di Indonesia berdasarkan tingkat penjualan ekspor karet alam dalam bentuk barang jadi SIR adalah PT. Kirana Megatara dan entitas anaknya (secara kolektif disebut "KM" atau sebagai "Perusahaan").

Kekuatan dan kelemahan merupakan faktor internal perusahaan yang bisa dikontrol, sementara peluang dan ancaman merupakan faktor eksternal yang sulit atau tidak dapat dikontrol oleh perusahaan. Analisa faktor internal dan eksternal berfungsi sebagai alat perencanaan strategis guna memaksimalkan kekuatan dan peluang serta meminimalkan kelemahan dan ancaman yang ada. Selain itu, KM juga perlu membuat sistem manajemen dan strategi bisnis yang sesuai dengan tuntutan lingkungan. Untuk mengetahui apakah penerapan strategi perusahaan telah berjalan sesuai dengan visi dan misinya, maka perlu dilakukan suatu penilaian kinerja. Dengan adanya penilaian kinerja maka perusahaan dapat mengetahui efektifitas dari penerapan suatu strategi, rentang waktu dan person in charge.

BSC menerjemahkan strategi perusahaan ke dalam seperangkat ukuran kinerja komprehensif yang bertujuan untuk mencapai visi perusahaan. Pendekatan BSC dilihat dari 
empat perspektif, yaitu keuangan, pelanggan, proses bisnis internal, serta pembelajaran dan pertumbuhan.

Bertolak dari latar belakang di atas, maka perlu dilakukan suatu analisa strategi yang perlu diterapkan untuk meningkatkan daya saing KM. Oleh karena itu, penelitian ini diberi judul "ANALISIS IFE, EFE, DAN BALANCE SCORECARD GRUP PERUSAHAAN KIRANA MEGATARA".

\section{Tujuan Penelitian}

a. Untuk mengkaji faktor internal perusahaan terhadap peningkatan keunggulan bersaing KM.

b. Untuk mengetahui dan menganalisa faktor eksternal perusahaan terhadap keunggulan bersaing KM.

c. Merumuskan langkah-langkah dalam merancang balance scorecard sebagai alat pengukur kinerja dan membuat strategi yang tepat.

\section{LANDASAN TEORI}

\section{Visi, Misi, dan Strategi Perusahaan}

Visi adalah rangkaian kalimat yang menyatakan cita-cita atau impian sebuah perusahaan yang ingin dicapai di masa depan (Wibisono, 2006:43). Visi menggambarkan apa yang ingin dicapai perusahaan dalam jangka panjang dan digunakan sebagai acuan dalam menentukan tindakan serta keputusan yang perlu diambil perusahaan. Visi harus dapat menginspirasi dan dijadikan dasar dalam membuat perencanaan strategis.

Misi adalah sesuatu yang mendefiniskan tujuan utama perusahaan. Misi adalah kalimat yang menyatakan tujuan atau alasan eksistensi organisasi, yang memuat apa yang disediakan perusahaan kepada masyarakat, baik berupa produk maupun jasa (Wibisono, 2006:46). Misi tidak seperti strategi dan tujuan yang dapat dicapai seiring dengan waktu. Misi dapat dianggap sebagai kompas yang membimbing perusahaan.

Strategi merupakan cara perusahaan untuk mencapai tujuan yang diinginkan. Strategi terdiri dari pendekataan-pendekatan bisnis yang dikembangkan oleh manajemen untuk menarik dan menyenangkan pelanggan, menumbuhkan bisnis, dan mencapai tujuan kinerja.

\section{Faktor Internal Perusahaan}

Analisis faktor internal sering diarahkan pada pemasaran, kondisi keuangan dan akuntansi, sumber daya manusia, serta struktur organisasi dan manajemen (David, 2011). Kekuatan dan kelemahan merupakan faktor internal perusahaan. Perusahaan dapat menggunakan Matriks Internal Factors Evaluation (IFE) untuk menganalisa faktor-faktor internal. Data dan informasi internal perusahaan dapat diihat dari manajemen keuangan, sumber daya manusia, pemasaran, sistem informasi, dan produk.

\section{Faktor Eksternal Perusahaan}

Faktor eksternal perusahaan sangat mempengaruhi pertumbuhan perusahaan dalam menentukan arah serta tindakan yang berpengaruh terhadap penentuan strategi pemasaran bagi perusahaan. Menurut David (2011) faktor eksternal perusahaan dibagi menjadi lima kategori besar, yaitu faktor ekonomi, faktor sosial, budaya, demografi, dan lingkungan, faktor politik, pemerintahan, dan hukum, faktor teknologi, dan faktor kompetitif

\section{Analisa SWOT}

Analisa SWOT merupakan sebuah metode per`encanaan strategis yang digunakan untuk mengevaluasi kekuatan (strengths), kelemahan (weaknesses), peluang (opportunities), dan ancaman (threats) dalam suatu bisnis. Proses ini melibatkan penentuan tujuan yang spesifik dari spekulasi bisnis dan mengidentifikasi faktor internal serta eksternal yang mendukung dan yang tidak dalam pencapaian tujuan tersebut. Matriks SWOT menggambarkan bagaimana manajemen dapat mencocokkan peluang dan ancaman serta kekuatan dan kelemahan untuk menghasilkan strategi yang efektif (Umar 2003:224). 


\section{Balance Scorecard sebagai Sistem Pengukuran Kinerja}

Kaplan dan Norton (1996) mendefinisikan balance scorecard (BSC) sebagai seperangkat pengukuran yang memberikan pandangan bisnis yang cepat dan komprehensif bagi manajer puncak, termasuk pengukuran keuangan yang menjelaskan hasil dari kejadian yang telah terjadi.

Empat perspektif BSC (Kaplan, 2004:36-49), digambarkan dalam peta strategi dengan menggunakan empat perspektif BSC (Kaplan, 2004:36-49):

a. Perspektif keuangan: Strategi menyeimbangkan dorongan pertentangan antara jangka pendek dan jangka panjang. Kondisi keuangan suatu perusahaan dapat diukur melalui dua pendekatan umum, yaitu revenue growth dan produktivitas.

b. Perspektif pelanggan: Strategi berdasarkan target segmen pelanggan dimana unit bisnis berkompetisi dan pengukuran dari tampilan unit bisnis untuk pelanggan dalam segment yang ditargetkan ini.

c. Perspektif proses bisnis internal: Proses bisnis internal mengerjakan komponen utama dari suatu strategi perusahaan, untuk menghasilkan dan mengirim usulan hasil kepada pelanggan. Proses bisnis internal terdiri dari: manajemen operasi, manajemen pelanggan, proses inovasi, serta proses sosial dan kebijakan.

d. Perspektif pembelajaran dan pertumbuhan: Perspektif ini menjelaskan intangible asset suatu perusahaan dan peran mereka dalam strategi.

\section{Kerangka Pemikiran}

Membuat peta strategi perusahaan dengan analisa IFE, EFE, dan SWOT yang didasarkan pada visi dan misi perusahaan. Peta strategi dihubungkan dengan empat perspektif yang ada dalam BSC, yaitu perspektif keuangan, pelanggan, proses bisnis internal, serta pembelajaran dan pertumbuhan.

\section{METODOLOGI PENELITIAN}

\section{Jenis dan Metode Penelitian}

Metode penelitian yang digunakan adalah Metode Penelitian Deskriptif (Descriptive Research Method). Metode deskriptif merupakan suatu prosedur pemecahan masalah yang diselidiki dengan menggambarkan keadaan subjek atau objek dalam penelitian yang berupa perusahaan dengan kondisi saat ini berdasarkan fakta-fakta yang ada.

Penelitian ini juga memfokuskan pada studi kasus, yang merupakan penelitian terperinci mengenai suatu obyek tertentu selama waktu tertentu dengan mendalam dan menyeluruh sebagai suatu keutuhan yang terintegrasi, yang bertujuan untuk mengembangkan pengetahuan yang mendalam mengenai obyek yang bersangkutan. Kasus yang pernah terjadi di KM seperti komplain dari pelanggan karena kualitas produk tidak sesuai spesifikasi, kekurangan supply karet alam karena petani memilih menjual ke kompetitor, dan turunya harga karet yang menyebabkan petani tidak mau menyadap karet.

\section{Sumber dan Teknik Pengumpulan Data}

Penelitian menggunakan data primer dan sekunder, dengan penjelasan berikut:

a. Data Primer

Data diperoleh dengan melakukan riset langsung ke lapangan dan mendatangi obyek penelitian, dengan cara: studi lapangan, pengamatan, wawancara dengan narasumber yang mempunyai peranan penting dalam proses kunci di perusahaan.

b. Data sekunder

Data diambil dengan cara mengumpulkan data dari arsip-arsip dan catatan-catatan di perusahaaan, seperti keuangan perusahaan dan struktur organisasi perusahaan. Selain itu, dilakukan juga studi kepustakaan untuk memperoleh data sekunder dengan membaca, mengumpulkan, mencatat, dan mempelajari text book serta buku-buku pelengkap dan referensi, seperti: jurnal, buletin, majalah, media cetak lainnya, dan internet. 


\section{Teknik Pengolahan dan Analisis Data}

Data dan informasi diolah secara kuantitatif dan dianalisis secara kualitatif berdasarkan konsep-konsep manajemen strategis. Analisis kuantitatif digunakan untuk menganalisis lingkungan makro dan mikro yang diperlukan dalam penentuan posisi yang terbaik bagi organisasi untuk merumuskan strategi jangka panjang. Sedangkan analisis kualitatif digunakan untuk mendapatkan gambaran mengenai visi, misi, tujuan organisasi, serta mengidentifikasikan faktor-faktor internal dan eksternal perusahaan. Penyusunan strategi didasarkan pada analisis faktor internal dan ekstenal perusahaan. BSC juga berperan penting dalam perumusan dan perencanaan strategis, untuk menterjemahkan seluruh strategi perusahaan ke dalam aktivitas operasional perusahaan dengan disertai menimalkan biaya yang terjadi di tingkat operasional.

Langkah-langkah melakukan analisa terhadap penelitian ini adalah sebagai berikut:

a. Melakukan analisa terhadap visi, misi, tujuan, dan strategi perusahaan

b. Melakukan analisa matriks IFE, EFE, dan SWOT

c. Menyusun kerangka Balance Scorecard (BSC)

d. Membuat peta strategi serta membahas strategi yang tepat

\section{Teknik Perancangan Balance Scorecard}

Teknik perancangan BSC dilakukan dengan melakukan analisis visi dan misi perusahaan, serta melihat kinerja perusahaan, kemudian dilanjutkan dengan merancang Balance Scorecard dengan menggunakan Strategy Map Balance Scorecard yang disesuaikan dengan empat perspektif yang ada dalam BSC, yaitu: keuangan, pelanggan, proses bisnis internal, serta pembelajaran dan pertumbuhan.

Analisis visi dan misi perusahaan akan menghasilkan sasaran strategis untuk masingmasing perspektif pengukuran. Sasaran strategis ini bertujuan untuk memgfokuskan proses pengukuran kinerja pada sasaran-sasaran strategis utama

perusahaan yang telah ditentukan kemudian ditampilkan dalam sebuah peta strategis perusahaan yang menggambarkan hubungan masing-masing sasaran antara satu perspektif dengan perspektif lainnya.

Setelah peta strategis dibuat, maka perlu ditetapkan pula suatu ukuran strategis. Terdapat dua ukuran strategis yang dapat digunakan sebagai indikator pengukuran berdasarkan konsep BSC, yaitu indikator kinerja (lagging indikator) dan indikator pemicu kinerja (leading indikator).

\section{ANALISIS HASIL DAN PEMBAHASAN Matriks Internal Factor Evaluation (IFE)}

Matriks IFE digunakan untuk mengetahui seberapa besar peranan dari faktor-faktor internal di perusahaaan. Dalam menyusun matriks IFE, maka diperlukan analisis dan identifikasi mengenai faktor internal perusahaan, yang terdiri dari kekuatan dan kelemahan yang dimiliki oleh KM, yaitu:

\begin{tabular}{|c|c|c|c|}
\hline Faktor Internal Utama & Bobot & Rating & Bobot Score \\
\hline \multicolumn{4}{|l|}{ Kekuatan } \\
\hline $\begin{array}{l}\text { 1. } 15 \text { pabrik yang tersistematis dan tersebar pada sumber-sumber karet di Indonesia, } \\
\text { dengan produksi terbesar di Indonesia }\end{array}$ & 0.3 & 4 & 1.2 \\
\hline $\begin{array}{l}\text { 2. Bekerja sama dengan } 20 \text { besar perusahaan pabrik ban dunia dengan kontrak jangka } \\
\text { panjang antara } 6-12 \text { bulan }\end{array}$ & 0.25 & 3 & 0.75 \\
\hline 3. Mematuhi dan memenuhi regulasi standar pabrik karet di Indonesia dan pelanggan & 0.1 & 3 & 0.3 \\
\hline \multicolumn{4}{|l|}{ Kelemahan } \\
\hline $\begin{array}{l}\text { 1. Sangat tergantung kepada supply karet dari petani dan trader, baik dari kuantiti yang } \\
\text { tidak menentu dan kualitas yang tidak konsisten }\end{array}$ & 0.25 & 1 & 0.25 \\
\hline 2. Produktivitas tanaman karet menurun saat musim rontok/trek dan musim & 0.1 & 2 & 0.2 \\
\hline Total Nilai & $\mathbf{1 . 0 0}$ & & 2.70 \\
\hline
\end{tabular}

Matriks Eksternal Factor Evaluation (EFE)

Matriks EFE digunakan untuk mengevaluasi dan mengetahui seberapa besar pengaruh peluang dan ancaman eksternal perusahaaan saat ini. Dalam menyusun matriks EFE, 
diperlukan informasi seperti ekonomi, sosial, budaya, pemerintahan, dan kompetisi untuk dilakukan analisis terhadap faktor-faktor ekternal utama perusahaan yang terdiri dari peluang dan ancaman.

\begin{tabular}{|c|c|c|c|}
\hline Faktor Eksternal Utama & Bobot & Rating & Bobot Score \\
\hline \multicolumn{4}{|l|}{ Peluang } \\
\hline $\begin{array}{l}\text { 1. Indonesia sebagai penghasil karet alam nomor } 2 \text { di dunia mencapai } 3.232 \text { ribu ton } \mathrm{kg} \\
\text { pada tahun } 2015\end{array}$ & 0.2 & 4 & 0.8 \\
\hline $\begin{array}{l}\text { 2. Penggunaan karet alam di dunia yang semakin meningkat } 35 \% \text { menjadi } 42 \% \\
\text { dibandingkan karet sintetis }\end{array}$ & 0.2 & 4 & 0.8 \\
\hline $\begin{array}{l}\text { 3. Produktivitas pohon karet di Indonesia masih di bawah negara pesaing, yaitu } 1.43 \\
\mathrm{~kg} / \mathrm{ha}\end{array}$ & 0.15 & 3 & 0.45 \\
\hline \multicolumn{4}{|l|}{ Ancaman } \\
\hline 1. Harga karet alam yang tidak stabil & 0.2 & 2 & 0.4 \\
\hline 2. Nilai tukar mata uang Rupiah terhadap mata uang asing tidak yang tidak stabil & 0.1 & 2 & 0.2 \\
\hline 3. Persaingan dengan perusahaan-perusahaan karet di dalam dan luar negeri & 0.15 & 3 & 0.45 \\
\hline Total Nilai & 1.00 & & 3.10 \\
\hline
\end{tabular}

Berdasarkan hasil penyusunan matrik IFE dengan rata-rata tertimbang sebesar 2.70 dan matriks EFE dengan rata-rata tertimbang 3.10, maka perusahaan berada pada kuadran II yaitu growth and build, dengan strategi perusahaan sebagai berikut focus on tire makers, build new factory, sustainable sourcing, dan operational excellence.

\section{Matriks SWOT}

Matriks SWOT menganalisis faktor internal dan eksternal yang dapat dihadapi oleh perusahaan untuk menghasilkan strategi alternatif yang dapat dihasilkan.

\section{Matriks SWOT PT Kirana Megatara}

\begin{tabular}{|c|c|c|}
\hline $\begin{array}{l}\text { IFE } \\
\text { EFE }\end{array}$ & $\begin{array}{l}\text { Strengths }-S \\
\text { (Kekuatan) }\end{array}$ & $\begin{array}{l}\text { Weaknesses - W } \\
\text { (Kelemahan) }\end{array}$ \\
\hline 包 & $\begin{array}{l}\text { Strategi SO: } \\
\text { 1. Optimalisasi kapasitas produksi pabrik untuk memenuhi } \\
\text { permintaan SIR di dunia. (S1, O1) } \\
\text { 2. Meningkatkan kualitas produksi sehingga menjadi mitra } \\
\text { utama pelanggan dalam memasok karet remahan. }(\mathrm{S} 2, \mathrm{~S} 3 \text {, } \\
\text { O1) } \\
\text { 3. Investasi pabrik baru untuk memenuhi permintaan produk } \\
\text { karet remahan di dunia. (S1, S2, O1, O2) }\end{array}$ & $\begin{array}{l}\text { Strategi WO: } \\
\text { 1. Memberikan pembinaan dan penyuluhan cara perawatan } \\
\text { dan penyadapan karet yang baik kepada kelompok tani, } \\
\text { sehingga kualitas karet sesuai standar, meningkatkan } \\
\text { produktifitas, dan dipercaya pelanggan. (O2, O3, W1, } \\
\text { W2) } \\
\text { 2. Menjalankan program CSR replanting tanaman karet, } \\
\text { dengan memberikan bibit karet dan pupuk sehingga } \\
\text { adanya sustainability karet. (O1, W2) }\end{array}$ \\
\hline 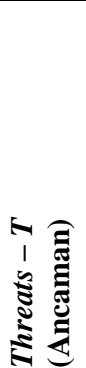 & $\begin{array}{l}\text { Strategi ST: } \\
\text { 1. Fokus pembelian ke smallholders (petani) dibandingkan } \\
\text { ke traders, sehingga dapat memberikan harga beli yang } \\
\text { lebih baik dan smallholders akan berkomitmen menjual } \\
\text { ke perusahaan dibandingkan ke kompetitor. (S1, T2) } \\
\text { 2. Melakukan hedging kurs USD untuk mendapatkan } \\
\text { kepastian konversi nilai USD ke IDR. (S1, T1) } \\
\text { 3. Meningkatkan penjualan LTC sehingga mendapatkan } \\
\text { jaminan kepastian order dan harga beli dari pelanggan. } \\
\text { (S1, T1) }\end{array}$ & $\begin{array}{l}\text { Strategi WT: } \\
\text { 1. Meningkatkan kualitas bahan baku karet agar tidak ada } \\
\text { SIR reject, sehingga buyer tetap konsisten membeli dari } \\
\text { perusahaan. (W1, T2, T3) } \\
\text { 2. Berkordinasi dengan pemerintah untuk menjaga pasokan } \\
\text { karet dan eksport SIR sehingga harga karet menjadi stabil. } \\
\text { (W1, T1) }\end{array}$ \\
\hline
\end{tabular}

\section{Pemetaan Strategi}

Berdasarkan strategi BSC KM maka dilakukan pemetaan untuk mengintegrasikan ke empat perspektif menjadi tujuan strategi objektif perusahaan 


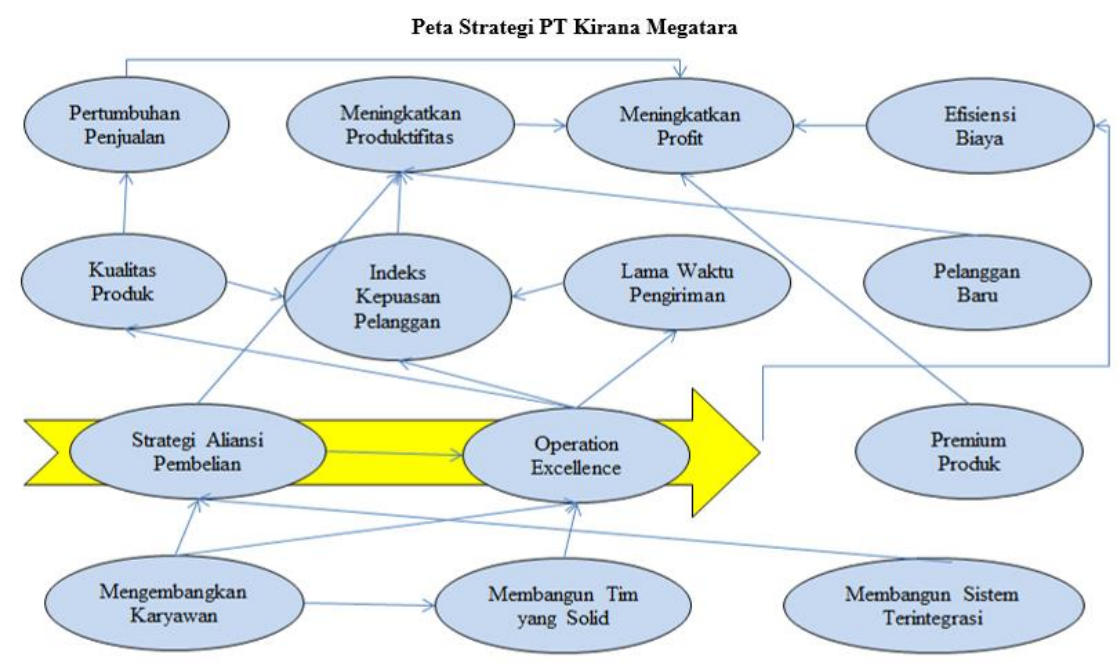

\section{Gambar 1 \\ Pemetaan Strategi}

\section{KESIMPULAN DAN SARAN \\ Kesimpulan}

Kesimpulan dari analisis dan penelitian yang dilakukan adalah:

1. Perusahaan lebih berfokus kepada penilaian keuangan dan pencapaian target perusahaan dalam pengukuran kinerja perusahaan, yaitu untuk memenuhi perspektif keuangan seperti pertumbuhan penjualan dan peningkatan laba.

2. KM sebagai perusahaan pengolahan industri karet remahan mempunyai pabrik-pabrik yang tersebar di area sumber karet alam, dapat memanfaatkan keunggulannya untuk bersaing dengan perusahaan dengan industri sejenis di Indonesia.

3. Potensi perkembangan industri pengolahan karet alam remahan Indonesia masih sangat besar. Hal ini berdasarkan faktor alam yang sesuai untuk industri ini dan permintaan pasar yang besar terutama untuk industri ban kendaraan. Sedangkan beberapa faktor yang menjadi kelemahan adalah kualitas karet alam dari petani yang tidak konsiten dan efektifitas panen karet yang masih belum maksimal.

4. Kerjasama dengan dengan 20 besar perusahaan pabrik ban dunia dengan kontrak jangka panjang, merupakan salah satu pendukung kepastian bisnis perusahaan dalam pertumbuhan penjualan.

5. KM sudah menjalankan sebagian dari sisi perspektif non-keuangan, yaitu pengembangan terhadap karyawan, kaderisasi dan ketersediaan karyawan di posisi kunci. Perusahaan mempunyai berbagai jenis program pelatihan dan training untuk karyawan, sehingga Saran dapat menjunjang pencapaian tujuan jangka panjang perusahaan.

Berdasarkan hasil analisis dan penelitian, didapatkan saran-saran yang perlu diperhatikan agar penerapan matriks SWOT dan balance scorecard di KM dapat berhasil:

1. Fokus kepada pelanggan dengan menciptakan nilai untuk pelanggan seperti memproduksi produk kualitas terbaik untuk menghindari produk cacat atau rusak, mengembangkan produk premium. Dengan ertujuan untuk meningkatkan perspektif keuangan seperti pertumbuhan penjualan dan peningkatan laba.

2. Perusahaan melakukan pembelian dengan fokus ke smallholders (petani, kelompok tani), untuk mendapatkan harga beli yang lebih baik untuk perusahaan dan smallholders, sehingga dapat memberikan nilai untuk pemasok.

3. Perusahaan perlu melakukan pengembangan dari sisi teknologi, yaitu implementasi sistem di seluruh depo KM yang terintegrasi dengan sistem di pabrik, sehingga dapat meningkatkan efisiensi proses dan kontrol. 
4. Strategi dan program rencana perusahaan harus dikomunikasikan kepada seluruh karyawan terutama bagian yang memegang peranan penting dalam proses bisnis di perusahaan, yaitu bagian pembelian, produksi, dan penjualan.

5. Secara rutin menjalankan program-program sosial yang berhubungan dengan petani karet, seperti pemberian bibit karet untuk replanting, pembinaan dan penyuluhan untuk perawatan dan sadap karet, serta pemberian pupuk untuk petani.

6. Penelitian lebih lanjut mengenai keberlanjutan dan ketelusuran dari karet alam yang diproduksi oleh perusahaan, dengan tujuan untuk nilai tambah dari pelanggan.

\section{DAFTAR PUSTAKA}

David, F. R. (2011). Strategic Management Concepts and Cases (13 ${ }^{\text {th }}$ ed.). Pearson Prentice Hall Inc.

Gakpindo. Data dan Peraturan Perkaretan di Indonesia. Retrieved November 15, 2016 from http://www.gapkindo.org/index.php?option=com_content\&view=article\&id=129\& Itemid=27.

Gakpindo. Analisis Pasar Karet. Retrieved Juli 01, 2017 from https://www.dropbox.com/s/9szszyv4tr8no9y/1.\%20ANALISIS\%20PASAR\%20JANU ARI\%202017.pdf?dl=0.

Johnson, G., Scholes, K., \& Whittington, R. (2008). Exploring Corporated Strategy. England: Pearson Education Limited.

Kaplan, R. S. \& Norton, D. P. (2004). Strategy Maps Converting Intangible Asset into Tangible Outcomes. Boston: Harvard Business School.

Kaplan, R. S. (2010). Conceptual Foundations of Balanced Scorecard. Boston Massachussets: Harvard Business School.

Kaplan, R. S. \& Norton, D. P. (1996). Translating Strategy into Action the Balance Scorecard. Boston: Harvard Business School.

Niven, P. R. (2006). Balance Scorecard Step-by-Step Maximizing Performance and Maintaining Results ( $2^{\text {nd }}$ ed.). New Jersey: John Wiley \& Sons Inc. Hoboken.

Porter, M. E. (2008). The Five Competitive Forces that Shape Strategy. Harvard Business Review.

PT Kirana Megatara. (2016). Annual Report dan Prospektus PT Kirana Megatara.

SGX. Singapore Exchange Rubber Price. Retrieved Maret 20, 2017 from http://sgx.com/wps/portal/sgxweb/home/!ut/p/a1/04_Sj9CPykssy0xPLMnMz0vMAfGj zOKNHB1NPAycDSz9wwzMDTxD_Z2Cg8PCDANdjYEKIoEKDHAARwNCsP1o8BK8JhQkBthkO6oqAgAzDYPQQ!!/d15/d5/L2dBISEvZ0FBIS9nQSEh/.

Umar, H. (2003). Metode Riset Bisnis. Jakarta: Gramedia

Wibisono, D. (2006). Manajemen Kinerja. Jakarta: Erlangga. 